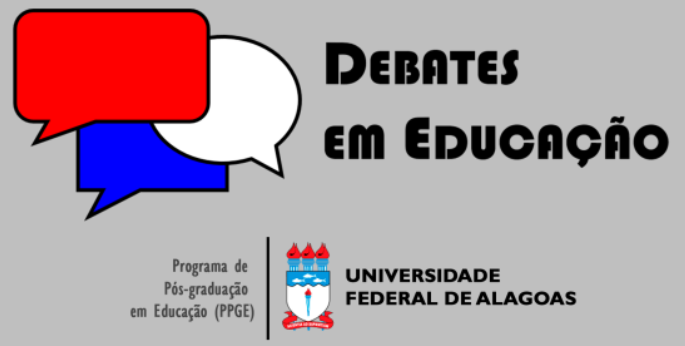

ISSN Eletrônico 2175-6600

Vol. 12 | No. 27 | Maio/Ago. | 2020

Débora Nunes de Sousa Lima

(9) iD

Universidade de Brasília (UnB)

deborareby@hotmail.com

\section{Anabelle Santos Lages}

(9) iD

Universidade Federal de Alagoas (UFAL) anabellelages@yahoo.com.br

\section{EDUCAÇÃO, RAÇA E CLASSE: UM}

ESTUDO SOBRE O APRISIONAMENTO

PROVISÓRIO NA COMARCA DE ARAPIRACA/AL

\section{RESUMO}

Este trabalho objetivou compreender, a partir de levantamento e análise do perfil dos acusados de furto, roubo e estelionato de processos judiciais em curso na $5^{\mathrm{a}}$ vara criminal de Arapiraca/AL, a materialização desses elementos no sistema punitivo brasileiro não apenas para confirmar os dados já produzidos acerca do encarceramento em massa, mas para alargar, a partir de uma análise inter-relacional, a compreensão de determinações que atravessam e constituem as trajetórias de alguns indivíduos. A metodologia empreendida na pesquisa foi bibliográfica e documental, tendo como escopo material o contingente de 263 processos criminais. A pesquisa constatou formas de punição não formal por parte do sistema de justiça criminal, relativas à trajetória dos presos sem condenação e não ao ato criminoso em si, tais quais os marcadores sociais da diferença e do estigma, como a cor da pele, a pouca desenvoltura diante das autoridades do sistema de justiça criminal, resultante da baixa escolaridade, e a ausência de ocupação. Concluiu-se, tomando como comparativo os perfis dos acusados por furto e por estelionato, que o aprisionamento provisório é muito mais resultado das avaliações e julgamentos subjetivos e intersubjetivos dos agentes do sistema de justiça criminal sobre a trajetória dos acusados do que uma aplicação estrita da legislação.

Palavras-chave: Raça. Classe. Educação. Aprisionamento. Presos sem condenação.

\section{EDUCATION, RACE AND CLASS: A STUDY ON TEMPORARY IMPRISONMENT IN ARAPIRACA/AL}

\begin{abstract}
This study aimed to understand, based on a survey and analysis of the profile of those of those accused of theft, robbery and fraud in a court cases underway in the 5th criminal court in Arapiraca / AL, the materialization of these elements in the Brazilian punitive system not only to confirm the data already produced about mass incarceration, but to broaden, based on an -interrelational analysis, the understanding of determinations that cross and constitute the trajectories of some individuals. The methodology used in the research was bibliographic and documentary, having as a material scope the contingent of 263 criminal cases. The research found forms of nonformal punishment by the criminal justice system, related to the trajectory of prisoners without conviction and not to the criminal act itself, such as the social markers of difference and stigma, such as skin color, little resourcefulness before the authorities of the criminal justice system, resulting from low education, and the absence of occupation. It was concluded, taking as a comparison the profiles of the accused for theft and fraud, that the provisional imprisonment is much more a result of the subjective and intersubjective evaluations and judgments of the agents of the criminal justice system on the trajectory of the accused than a strict application of legislation.
\end{abstract}

Keywords: Race. Class. Education. Imprisonment. Prisoners without conviction.

Submetido em: 26/07/2019

Aceito em: 3 I/03/2020

Publicado em: 22/06/2020

do http://dx.doi.org/I0.28998/2 I 75-6600.2020v I 2n27p388-409 


\section{INTRODUÇÃO}

De acordo com o mais recente Levantamento Nacional de Informações Penitenciárias (INFOPEN, 20 17), o Brasil possui hoje um contingente populacional em situação de prisão de 726.7। 2 mil indivíduos. crescimento exponencial dessa taxa, fenômeno identificado como "encarceramento em massa" (WACQUANT, 1999) pode ser visualizado pelo índice de aprisionamento, que cresceu 74\% entre os anos 2005 a 2012, fazendo com que o país passasse a ocupar o $3^{\circ}$ lugar no ranking mundial de encarceramento, posicionando-se atrás apenas dos EUA e da China, (INFOPEN, 20 I7).

Ainda mais preocupante é o fato de que enquanto os dois primeiros colocados têm apresentado uma redução em suas taxas (no período entre 2008 e 20।4, os EUA reduziu 8\%, China reduziu 9\%), o Brasil parece caminhar no contrafluxo da história, aumentando, no mesmo período, em 33\% sua população carcerária. Dados mais recentes apontam que entre 2000 e 2016 o número de pessoas encarceradas no Brasil cresceu I57\% (INFOPEN, 20 I7), bem acima do crescimento natural da população em geral, tendo em vista que entre os anos de 2000 e 2010 houve um aumento demográfico de I2,3\% (IBGE, 20I0).

O perfil dos indivíduos encarcerados não chega a ser uma novidade para os interessados no tema, são homens, jovens entre 18 a 29 anos, negros (pretos e pardos), desempregados e moradores de regiões periféricas. A vulnerabilidade desses sujeitos torna-se ainda mais exposta quando se adiciona a escolaridade, mais da metade dos presos brasileiros não possuem o ensino fundamental completo (INFOPEN, 20 I7). Como demonstraram as reflexões teóricas de Fernandes (2014) e Souza (2009), e os dados gerais de Pochmann (20।0; 20I5) e do IBGE (20I5; 20I7), renda e escolaridade são dois aspectos absolutamente presentes na construção da classe e que também informam a trajetória de raça. Para fins de compreensão analítica da realidade optamos por não imputar fixidez à variável educação, quer como condição para a vulnerabilidade prisional, quer como prevenção profilática ao cometimento de crimes. Preferimos toma-la como elemento que orbita de forma contundente ao redor das variáveis raça e classe, indicando os caminhos pelos quais a sociedade deverá urgentemente percorrer caso queira enfrentar a epidemia do encarceramento de jovens negros de periferia.

Preliminarmente, importa destacar e justificar alguns conceitos fundamentais para a pesquisa e desenvolvidos neste artigo. Nesse sentido, quando falamos sobre "raça", o sentido analítico empregado é o de construção social, de identidade social, sentido cultural simbólico, que faz parte de um discurso sobre origem. Dessa forma, quando nos referimos à "raça", partimos de dois pressupostos: inexistência biológica de raças humanas (sabemos que, na espécie humana, não há o que possa ser identificado, cientificamente, como "raça") e construção social. "Raça”, na acepção empregada aqui, trata-se de algo que tem existência nominal, o qual produz efeitos no mundo social, e, portanto, só pode fazer sentido e ser real socialmente. 
Do mesmo modo, quanto à classe, o sentido utilizado é também de construção social e sociológica, do qual se valem instituições como o IBGE. Ademais, quando nos referimos à educação, compreenda-se esta como escolaridade/qualificação formal, no sentido empregado pelo MEC e aferido pelo IDEB. Por fim, quanto ao encarceramento e aprisionamento provisório, estes são desenvolvidos no texto conforme o investigado na pesquisa em comento, tendo por foco principal o estudo de um contingente específico dentre as pessoas aprisionadas: os presos sem condenação - indivíduos acusados pelo sistema de justiça criminal e mantidos em estabelecimentos prisionais mesmo antes de serem sentenciados.

Considerando este cenário e, com vistas a possibilitar análises mais concretas de fenômeno amplamente conhecido, este artigo objetiva apresentar a materialização, nos sujeitos encarcerados, das inter-relações dessas três variáveis macrossociológicas, quais sejam raça, classe e escolaridade. A fim de mostrar o resultado de tais arranjos, julgamos pertinente eleger uma localidade apta a funcionar como uma espécie de "tipo ideal" weberiano, razão pela qual Arapiraca foi escolhida. A cidade pode ser considerada caso limite, exatamente por conjugar de forma acentuada as características em relação às quais tomamos importantes nos debruçar para compreender o drama do sistema carcerário brasileiro.

Arapiraca, segunda maior cidade do estado de Alagoas, é um dos municípios mais desiguais e excludentes do Brasil, apresentando indicadores socioeconômicos que retratam o que Souza (2009) chamou de "ralé estrutural", uma classe brasileira excluída e invisibilizada, de despossuídos de competências psicossociais mínimas para a inserção e participação na moderna ordem competitiva capitalista, ou seja, um contingente de indivíduos que, antes mesmo de ser aprisionado pelo Sistema de Justiça Criminal através de um fato social qualificado como crime, fora punido em sua origem social.

A oportunidade de analisar o caso de uma cidade do Nordeste parece-nos especialmente necessária, posto que a região está ligada a sensíveis questões sociais, principalmente em razão da concentração de poder e de terras que deu causa a séculos de desigualdades. Alagoas desde os seus primórdios teve uma economia calcada na monocultura canavieira, com a presença de grandes latifundiários que, não raro, pautaram suas relações políticas e sociais por meio de disputas brutais por poder, desconsiderando por décadas, os direitos sociais e individuais da maior parcela da população (TENÓRIO, 2007). Tal histórico, aliado às questões raciais foi provocando o chamado ciclo cumulativo de desvantagens (HASENBALG, 1979), que pode ser compreendido como o resultado

(...) da discriminação racial no passado, cada nova geração de não-brancos está em posição de desvantagem porque se origina desproporcionalmente de famílias de baixa posição social. Mas, em acréscimo a isso, [...] a filiação racial deverá também interferir tanto nos processos de acumulação de (des)vantagens pelos filhos quanto em suas subsequentes carreiras como adultos. Isso implica que mesmo controlando pela posição social das famílias de origem, os filhos de pais não-brancos acumularão menos recursos competitivos que os filhos de pais brancos - incluindo níveis de habilidade, educação e aspirações e a própria adscrição racial. (HASENBALG, 1979, p. 208-209). 
Desdobramento de sua história, em todas as classificações feitas pelo estudo do Atlas da Exclusão Social no Brasil (POCHMANN, 20 I 0; 20I5), o estado de Alagoas aparece nas piores colocações, tendo quase um quarto de seus cidadãos vivendo em cidades com alto grau de exclusão social, o que significa dizer que aproximadamente 30\% dos seus habitantes estão situados em municípios cujos serviços públicos são precários e as oportunidades de educação e trabalho para os jovens, escassas. Quanto a esse aspecto, a observação de Pochmann (20।5, p. 85) é que "os 15,3 milhões de habitantes desses municípios com graves problemas sociais não podem esperar para que a "lógica do mercado" leve desenvolvimento até suas cidades".

Considerando todas essas variáveis, nossa investigação foi feita a partir das análises de dados primários ${ }^{1}$ colhidos dos processos judiciais em tramitação na $5^{a}$ vara criminal de Arapiraca entre os anos de 201। e 2017. Importa destacar que a metodologia empreendida na pesquisa foi bibliográfica e documental, tendo tomado como escopo material o contingente de 263 processos criminais. Por não se tratar dos objetivos deste artigo, optamos por nos afastar dos aspectos mais formais do sistema de justiça criminal, como a relação tipo de crime versus pena, por exemplo, centrando esforços no cruzamento regional das variáveis raça, classe e educação, vale dizer, a partir dos dados recolhidos, dirigimos nossos olhares às condições prévias ao encarceramento dessas pessoas.

Paralelamente, e para nos mantermos adstritos aos referenciais teóricos adotados, ralé estrutural (SOUZA, 2009) e "ciclo cumulativo de desvantagens" (HASENBALG, 1979), consideramos o furto e o roubo a melhor expressão das possibilidades delitivas daqueles que carregam os marcadores de nossa análise. Os chamados crimes de rua requerem antes uma oportunidade do que propriamente a chamada expertise, sendo praticados grande parte das vezes por sujeitos pertencentes a estratos sociais mais baixos e carecendo de qualificação profissional. Por outro lado, consideramos interessante trazer o crime de estelionato para a análise exatamente por nos servir como um comparativo analítico. Embora trate-se, como o furto e o roubo, de crime contra o patrimônio, o perfil dos criminalizados por estelionato em nada se assemelha com aqueles: são pessoas brancas, adultas, bem escolarizadas e qualificadas, todas empregadas formalmente.

Concomitantemente, foram trazidos dados secundários produzidos pelo IBGE (20|4), IPEA (2016), Pochmann (20I0; 20I5) e Governo de Alagoas (2017), que cumpriram a função de delimitar, a partir de estatísticas atualizadas, o quanto os fenômenos de raça e classe, ao mesmo tempo em que são constitutivos, incrementam sensibilidade à vulnerabilidade educacional dos sujeitos expostos à situação prisional. Consideramos igualmente importante nos valer do uso controlado e atualizado de estatísticas descritivas, contendo dados quantitativos derivados de fontes como o Levantamento Nacional de

\footnotetext{
' Cabe salientar que os dados primários utilizados neste trabalho quanto à raça dos indivíduos criminalizados não seguiram o critério de autodeclaração, uma vez que a raça é apreendida e imputada pelos agentes do Sistema de Justiça Criminal, em específico, por agentes policiais na feitura do Inquérito Policial e por agentes penitenciários no prontuário dos presos.
} 
Informações Penitenciárias (INFOPEN, 20 I 4; 20 I7); Mapa de Informações Penitenciárias da Secretaria de Estado de Ressocialização e Inclusão Social de Alagoas (SERIS/AL, 2017) e Mapa do Encarceramento e Mapa da Violência (PNUD, 20|4).

Por essa razão, nas seções seguintes destrinchamos as variáveis emprego/rendimento, raça e educação no município de Arapiraca, vis a vis aos dados nacionais sobre a matéria. Nosso intuito foi alargar a compreensão das determinações que atravessam e constituem as trajetórias de uma parcela dos indivíduos encarcerados naquele município o que, por sua vez, torna possível compreender não apenas as constrições às quais estão submetidos e, assim, entender regularidades percebidas em suas trajetórias, mas também possibilitar pesquisas que se interessem em investigar mais amiúde as relações entre níveis de escolaridade e aprisionamento.

\section{CLASSE, RAÇA E ENCARCERAMENTO EM ARAPIRACA}

Ao analisar as acusações em trâmite na $5^{a}$ vara criminal de Arapiraca, percebemos que os 263 processos resultaram em 321 pessoas acusadas. Em relação aos crimes de furto, roubo e estelionato 93,4\% foram praticados por homens, 83,5\% eram jovens entre 18 e 29 anos, 93,4\% eram negros, 75\% estavam solteiros. Quanto à escolaridade, somente 13 das 292 pessoas tinham concluído o ensino médio, enquanto I 58 eram apenas alfabetizadas.



Fonte: elaboração própria (2020). 
Gráfico 2 - Faixa etária dos criminalizados e/ou presos conforme o crime praticado

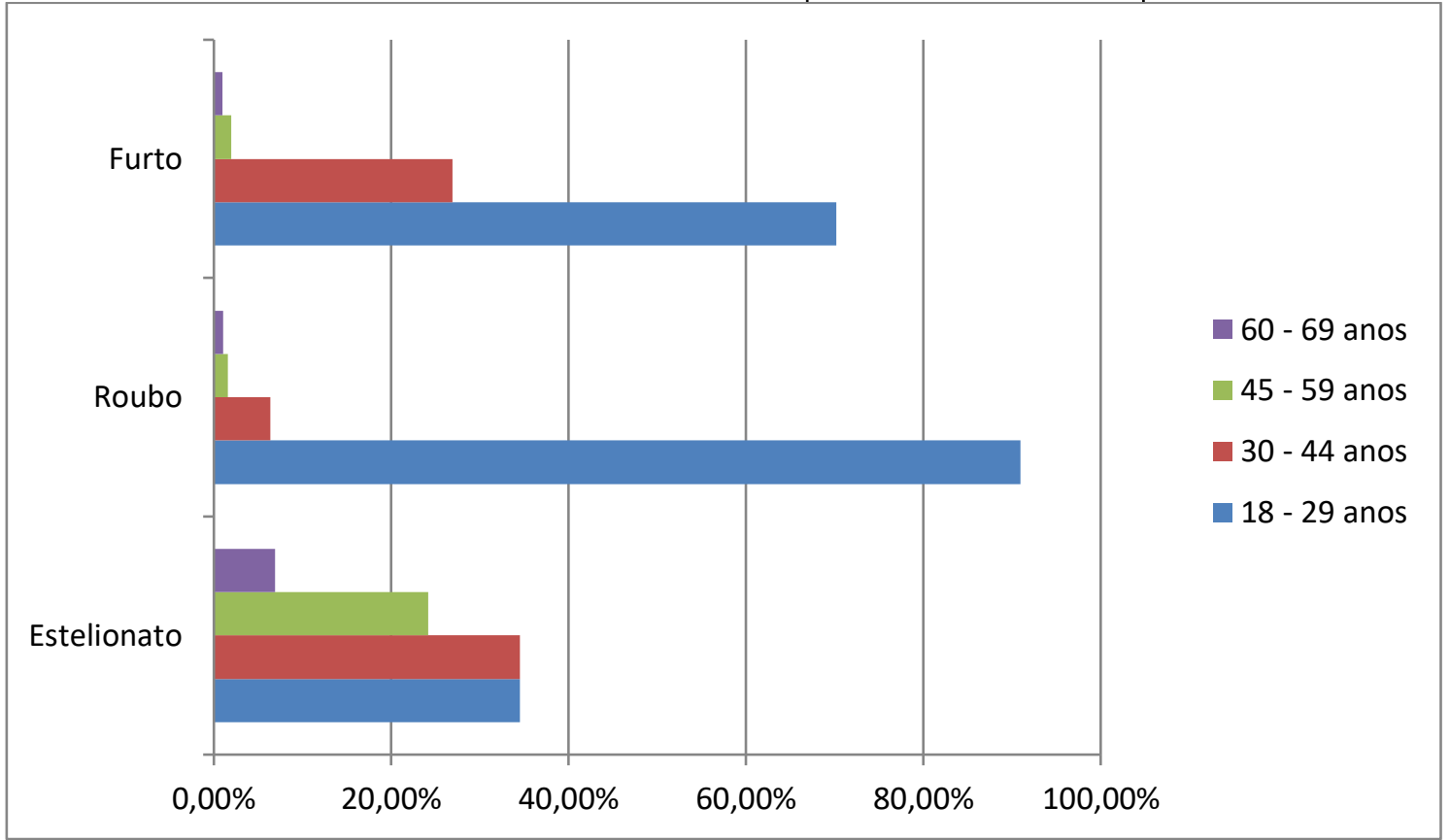

Fonte: elaboração própria (2020).

\section{Gráfico 3 - Estado civil dos criminalizados e/ou presos conforme o crime praticado}

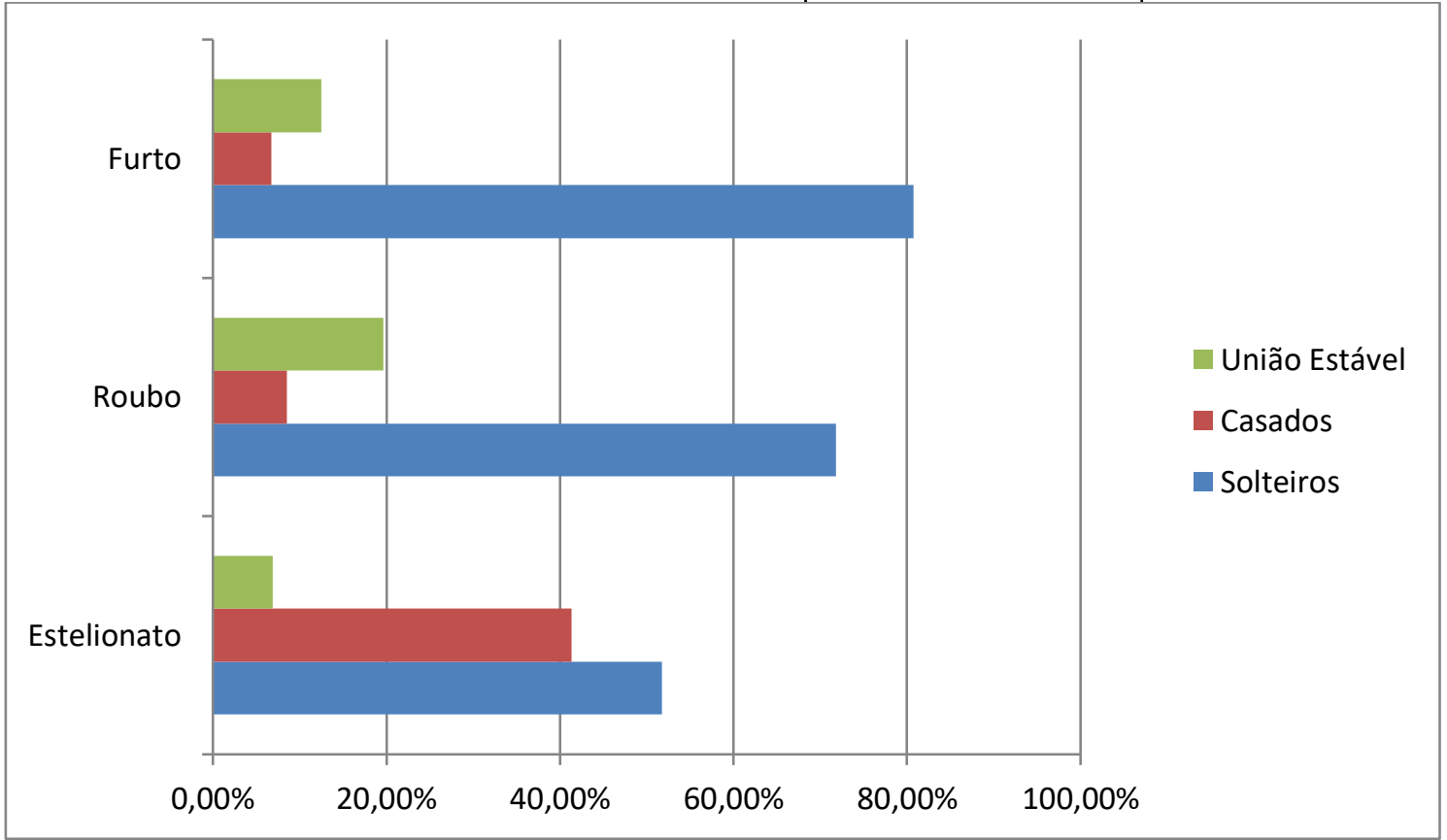

Fonte: elaboração própria (2020).

Renda e escolaridade são dois aspectos absolutamente presentes na construção da classe, marcando igualmente a trajetória de raça (FERNANDES, 20I4; SOUZA, 2009; POCHMANN, 20I0). Por essa razão e pela impossibilidade de estabelecer de forma direta, a partir dos processos analisados, as classes às quais pertencem os acusados, em um primeiro momento, identificamos o quantitativo de pessoas empregadas, desempregadas e em trabalho informal. Essas variáveis, conjugadas com os indicadores trabalho e rendimento do município, bem como com as taxas de desemprego, 
ocupação/desocupação e de rendimento do estado nos ajudarão a dar os primeiros contornos a respeito da classe à qual pertencem. Posteriormente, raça e escolaridade serão trazidos para integrar a análise.

Como se vê no gráfico abaixo, das 321 pessoas acusadas, 55 estavam empregadas no mercado de trabalho formal, 87 em trabalhos informais e 179, desempregadas. Quando aproximamos o olhar, das 104 pessoas acusadas de furto, apenas 6,73\% estavam empregadas formalmente, no de roubo, 10, 10\%, enquanto 100\% das pessoas envolvidas em processos de estelionato possuíam emprego formal.

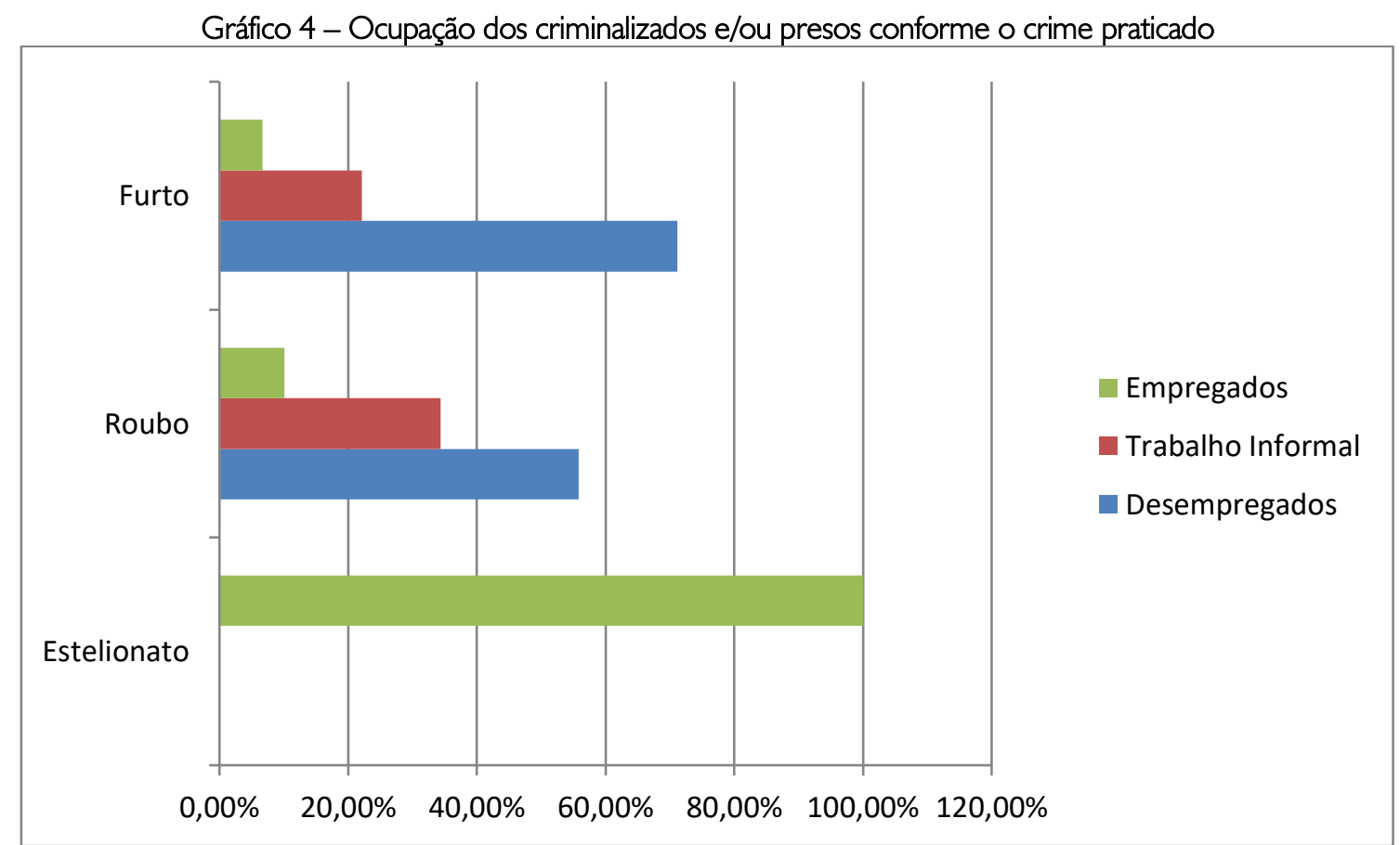

Fonte: elaboração própria (2020).

Quando se observa o indicador salário médio mensal dos trabalhadores formais de Arapiraca, a variável rendimento mostra o quão sensível é a situação do município, que ocupa a última posição entre as 33 localidades brasileiras que possuem uma população entre 200 e 250 mil habitantes. No cômputo geral dos 5.570 municípios, Arapiraca localiza-se na $4.253^{\circ}$ colocação, deixando-a entre os 1.500 municípios brasileiros com a pior média salarial mensal dos trabalhadores formais. Como evidencia o gráfico 5, que também complementa a tabela I, a redução do salário médio mensal em Arapiraca ocorreu com maior intensidade entre os anos de 201 I e 2013, período que coincide com parte do recorte temporal desta pesquisa. 
Tabela I - Salário médio mensal dos trabalhadores formais - posição dos municípios brasileiros com população entre 200 e 250 mil habitantes

\begin{tabular}{|c|c|c|c|}
\hline \multirow[b]{2}{*}{ Município } & \multirow[b]{2}{*}{ Estado } & Variável trabalho e rendimento & Posição \\
\hline & & $\begin{array}{l}\text { Salário médio mensal dos } \\
\text { trabalhadores formais }\end{array}$ & De 5.570 municípios \\
\hline Arapiraca & $\mathrm{AL}$ & 1,6 salários mínimos & $4.253^{\circ}$ \\
\hline Araraquara & SP & 2,8 salários mínimos & $315^{\circ}$ \\
\hline Alvorada & RS & 2,3 salários mínimos & $934^{\circ}$ \\
\hline Americana & SP & 3,0 salários mínimos & $220^{\circ}$ \\
\hline Cotia & SP & 3,4 salários mínimos & $112^{\circ}$ \\
\hline Colombo & PR & 2,5 salários mínimos & $580^{\circ}$ \\
\hline Cabo Frio & $\mathrm{RJ}$ & 2, I salários mínimos & $1559^{\circ}$ \\
\hline Chapecó & SC & 2,7 salários mínimos & $370^{\circ}$ \\
\hline Cabo de Santo Agostinho & PE & 2,6 salários mínimos & $460^{\circ}$ \\
\hline Chapecó & SC & 2,7 salários mínimos & $370^{\circ}$ \\
\hline Criciúma & SC & 2,6 salários mínimos & $470^{\circ}$ \\
\hline Dourados & MS & 2,6 salários mínimos & $460^{\circ}$ \\
\hline Divinópolis & MG & 2, I salários mínimos & $1559^{\circ}$ \\
\hline Hortolândia & SP & 4,6 salários mínimos & $25^{\circ}$ \\
\hline Indaiatuba & SP & 3,7salários mínimos & $66^{\circ}$ \\
\hline Itaboraí & $\mathrm{RJ}$ & 2,7 salários mínimos & $370^{\circ}$ \\
\hline Itapevi & SP & 3,7 salários mínimos & $66^{\circ}$ \\
\hline Itabuna & $\mathrm{BA}$ & 2,0 salários mínimos & $1987^{\circ}$ \\
\hline Jacareí & SP & 3,3 salários mínimos & $130^{\circ}$ \\
\hline Juazeiro & BA & 2, I salários mínimos & $1559^{\circ}$ \\
\hline Maracanaú & CE & 2, I salários mínimos & $1559^{\circ}$ \\
\hline Marília & SP & 2,7 salários mínimos & $370^{\circ}$ \\
\hline Magé & $\mathrm{RJ}$ & ।,8 salários mínimos & $3020^{\circ}$ \\
\hline Parauapebas & PA & 3,0 salários mínimos & $220^{\circ}$ \\
\hline Presidente Prudente & SP & 2,6 salários mínimos & $460^{\circ}$ \\
\hline Jacareí & SP & 3,3 salários mínimos & $130^{\circ}$ \\
\hline Rondonópolis & MT & 2,5 salários mínimos & $580^{\circ}$ \\
\hline Rio Verde & $\mathrm{GO}$ & 2,6 salários mínimos & $460^{\circ}$ \\
\hline Rio Claro & SP & 3,0 salários mínimos & $220^{\circ}$ \\
\hline Rio Grande & RS & 3,7 salários mínimos & $66^{\circ}$ \\
\hline Santa Luzia & $M G$ & 2,4 salários mínimos & $723^{\circ}$ \\
\hline Sobral & CE & 1,9 salários mínimos & $2500^{\circ}$ \\
\hline São Leopoldo & RS & 3, I salários mínimos & $176^{\circ}$ \\
\hline Sete Lagoas & $M G$ & 2,3 salários mínimos & $934^{\circ}$ \\
\hline
\end{tabular}

Fonte: elaborada a partir do IBGE (2017). 




Tabela 2 - Taxa de desemprego - 2012-20I5 (em \%)

\begin{tabular}{ccccc}
\hline BR/NE/AL & 2012 & 2013 & 2014 & 2015 \\
\hline Brasil & 6,2 & 5,9 & 6,9 & 9,6 \\
\hline Nordeste & 7,6 & 7,3 & 8,0 & 10,3 \\
\hline Alagoas & 9,9 & 10,0 & 11,6 & 15,3
\end{tabular}

Fonte: IBGE/PNAD (20I4).

Tabela 3 - Taxa de ocupação das pessoas de 10 anos e mais de idade - 2012-2015 (em \%)

\begin{tabular}{ccccc} 
BRNNE/AL & 2012 & 2013 & 2014 & 2015 \\
\hline Brasil & 61,8 & 61,2 & 61,9 & 58,6 \\
\hline Nordeste & 58,0 & 57,7 & 57,0 & 55,1 \\
\hline Alagoas & 51,4 & 52,0 & 50,0 & 44,9 \\
\hline
\end{tabular}

Fonte: IBGE/PNAD (20I4).

As tabelas acima e o cartograma abaixo mostram que as taxas de desemprego e de ocupação do estado de Alagoas são, respectivamente, as maiores e menores do Brasil. No entanto, a ironia reside no fato de que, ainda que exista uma crise no país desde 2014, Arapiraca tem crescido economicamente, estando entre as 126 cidades dentre as quais a oferta de empregos tem sido positiva em todos os anos desde 2002, ocupando o primeiro lugar nesse ranking (FOLHA, 20 16). Nos últimos três anos o mercado local recebeu uma filial de uma empresa de telemarketing com cerca de 1.600 ofertas de emprego, e um shopping center (GAZETAWEB, 20।4). No entanto, Alagoas registrou a maior taxa de desocupação do país, 17,2\%. 


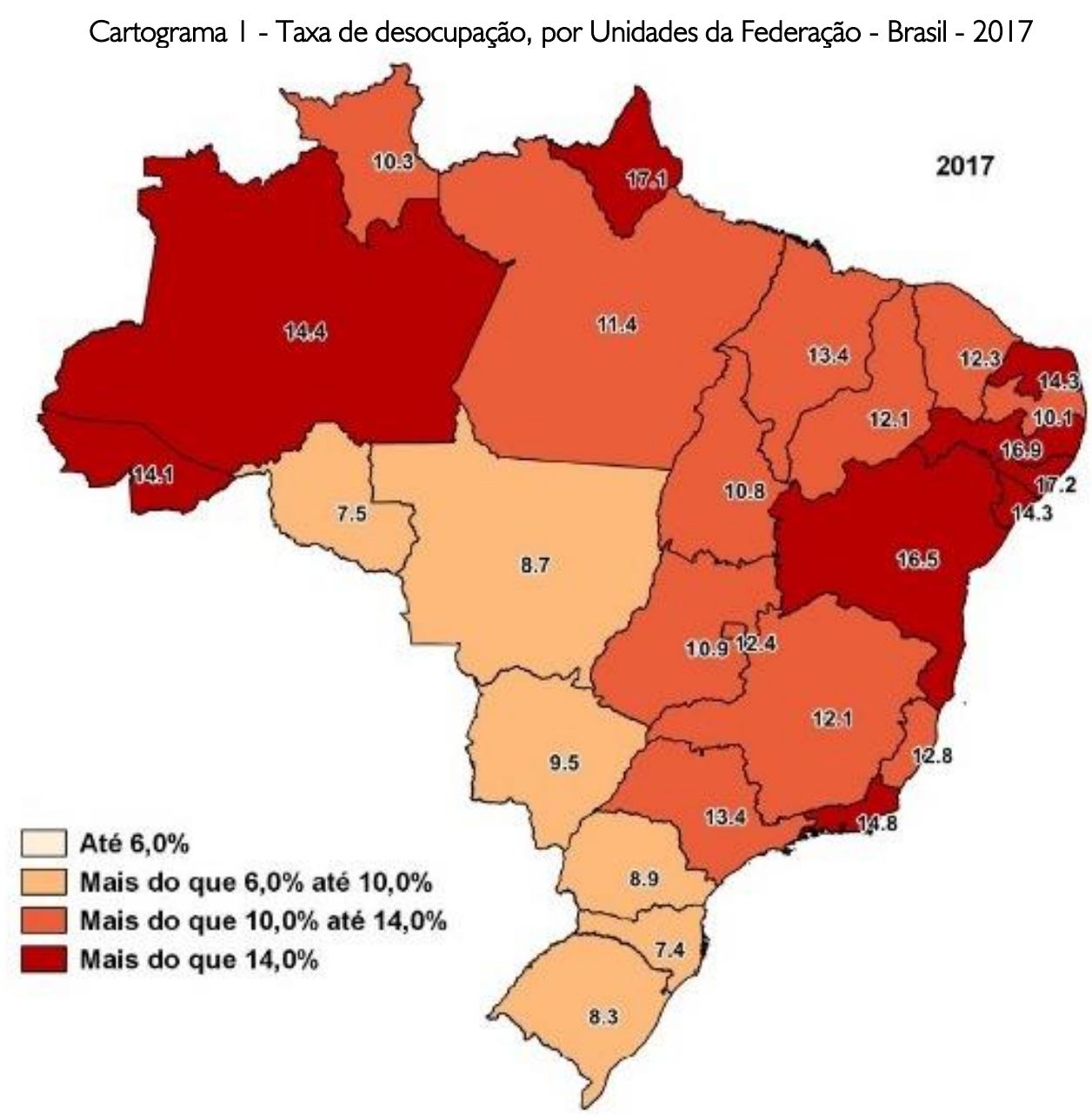

Fonte: síntese de indicadores sociais, IBGE (20|8).

Nesse sentido, nossa suspeita é que a não integração ao mercado de trabalho de indivíduos cujo perfil se aproxima daqueles que possuem processos em trâmite na $5^{a}$ vara criminal, dá-se por uma série de incapacidades relativas ao chamado habitus precário, na interpretação que Souza (2009) confere ao habitus (bourdieusiano). Classe invisibilizada e marginalizada ("ralé" estrutural), que se traduz num esquema de disposições comportamentais e de (não)incorporação de competências necessárias para a vida social no mundo capitalista hodierno, como a falta de conhecimento, no sentido de qualificação escolarizada, fato que os impossibilita competir por uma vaga de emprego, bem como os incapacita de pleitear espaço no trabalho informal, pois este demanda não apenas oportunidade como criatividade. A partir de uma análise mais ampla e comparativa dos dados pode-se notar a existência de uma severa dificuldade no processo de profissionalização e inclusão dos cidadãos alagoanos à competição socioeconômica. Este aspecto fica mais aparente quando se percebe que a taxa de ocupação, indicadora de trabalhos informais, também é inferior às taxas nacional e regional.

A respeito do rendimento auferido pelas pessoas que estão inseridas de alguma forma na ordem social competitiva, ainda que informalmente, observa-se na tabela abaixo que os trabalhadores em Alagoas têm um rendimento de quase $\mathrm{R} \$ 700$ (setecentos reais) a menos do que os trabalhadores nacionais. 
Embora se reconheça que o desenvolvimento econômico de um estado e o rendimento salarial que seus cidadãos dispõem para viver sejam apenas um estrato do que poderia ser considerado como desenvolvimento social, capaz de reduzir e atenuar as desigualdades históricas de uma população local, sabe-se que estas são questões importantes para apreender a qualidade de vida dessa sociedade de indivíduos.

Tabela 4 - Pessoas de 15 Anos ou mais de idade, ocupadas na semana de referência, com rendimento (R\$) - 20I2-20I5.

\begin{tabular}{|c|c|c|c|c|}
\hline BRNE/AL & 2012 & 2013 & 2014 & 2015 \\
\hline Brasil & 1.578 & 1.640 & 1.645 & 1.853 \\
\hline Nordeste & 1.006 & 1.050 & 1.018 & 1.213 \\
\hline Alagoas & 999 & 1.121 & 1.114 & 1.148 \\
\hline
\end{tabular}

Fonte: IBGE/PNAD (20|4).

Em específico quanto ao furto, das 104 pessoas acusadas, 21 foram processadas por tentativa, 52 por furto simples e 31 por furto qualificado - nesta modalidade enquadram-se, por exemplo, os furtos praticados por mais de uma pessoa ou cometidos mediante escalada e rompimento de barreira. Dentre as 104, 08 eram moradores de rua, II usuários de drogas, 12 agricultores. Trata-se de uma forma de imputar penas típicas do modelo neoliberal atual, que manifesta a situação paradoxal dos Estados, tanto do primeiro quanto do segundo mundo, de tentar reparar através de um "mais Estado" policial e penitenciário o "menos Estado" econômico e social, causa intrínseca à crescente e disseminada insegurança objetiva e subjetiva em todos os países (WACQUANT, 1999).

Quando percebida de forma apartada, a classe em si não consegue explicar as razões de, entre os pobres, um branco ter condições relativamente melhores de acesso à Justiça do que um negro, ou, por exemplo, conseguir incorporar esquemas de disposições mais aptos a lidar com as rotinas das práticas jurídicas, seja numa oitiva na polícia (saber fazer uso do seu direito de permanecer em silêncio), seja numa audiência (não constituir provas contra si). Tais dificuldades exemplificam o que Hasenbalg (1979) chamou de "ciclo cumulativo de desvantagens permanentes" que, corroborados pela discriminação e pelo preconceito mostram como deficiências educacionais impactam os sujeitos nas mais variadas situações da vida.

De acordo com os processos analisados e o levantamento de dados feito por nós, a maioria (mais de 90\%) dos indivíduos criminalizados é negra (pretos e pardos). Além disso, não ascendeu socialmente, sequer conseguiu obter escolaridade (compreendida como conclusão do ensino médio por pessoas maiores de 17 anos de idade), vive à margem, desempregada ou fazendo "bicos" (guardador de carros, ajudante de pedreiro, etc.) para sobreviver, não tem casa própria, mora no mesmo lugar de origem, quase sempre em bairros periféricos e vulneráveis, que sequer contam com saneamento básico. 
No entanto, quando comparamos, mesmo entre as pessoas pobres criminalizadas nesses processos, quando se trata de um pobre negro e um pobre branco há diferenças basilares na trajetória dos sujeitos. Em relação à educação, dentre as 36 pessoas analfabetas, apenas 02 são brancas; dentre as 09 pessoas que cursaram o ensino superior, somente 02 são negras, e todas as 09 estão envolvidas em processos sobre estelionato. Um aspecto dramático visto nos processos, no qual, também, percebemos uma diferença significativa quanto à raça, diz respeito à incidência de agressões disferidas por transeuntes, em ambientes públicos como a rua, contra os sujeitos acusados, quando da prisão em flagrante destes: dos 18 que foram agredidos, apenas 02 eram brancos.

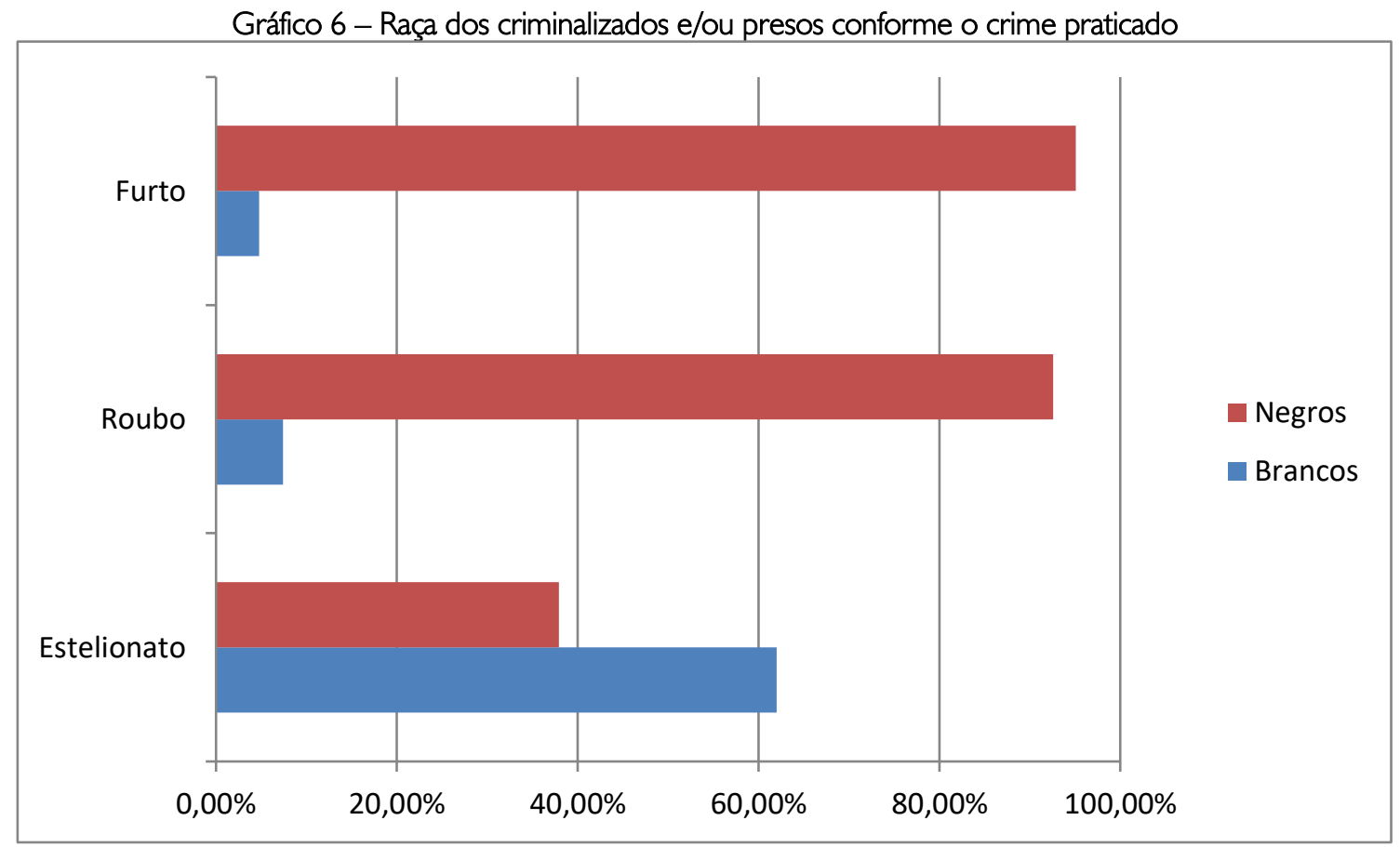

Fonte: elaboração própria (2020).

Quando a escala populacional e racial é ampliada, vê-se que os números do estado são proporcionalmente maiores do que os encontrados em âmbito nacional, embora estes continuem sendo elevados. De acordo com o INFOPEN de 2017, 53\% da população brasileira corresponde a negros, sendo que esses representam 64\% do contingente populacional em situação de prisão no Brasil. De acordo com o INFOPEN (2017), de todo o contingente populacional em situação de prisão no estado de Alagoas $80 \%$ são negros, embora a população negra represente $64 \%$ da população total do estado, como mostrou o último censo oficial brasileiro (IBGE, 20 I0). O que se observa é que nas duas escalas, estadual e nacional, a população negra é menor no total da população e maior no total de indivíduos aprisionados, o que demostra como o aprisionamento tem ocorrido de forma desproporcional entre brancos e negros. 
Tabela 5 - Raça, cor ou etnia das pessoas privadas de liberdade por UF

\begin{tabular}{|c|c|c|c|c|c|}
\hline UF & Branca & Negra & Amarela & Indigena & Outras \\
\hline AC & $5 \%$ & $95 \%$ & $0 \%$ & $0 \%$ & $0 \%$ \\
\hline AL & $20 \%$ & $80 \%$ & $0 \%$ & $0 \%$ & $0 \%$ \\
\hline AM & $16 \%$ & $84 \%$ & $0 \%$ & $0 \%$ & $1 \%$ \\
\hline AP & $9 \%$ & $91 \%$ & $1 \%$ & $0 \%$ & $0 \%$ \\
\hline BA & $11 \%$ & $89 \%$ & $0 \%$ & $0 \%$ & $0 \%$ \\
\hline CE & $15 \%$ & $84 \%$ & $1 \%$ & $0 \%$ & $0 \%$ \\
\hline DF & $17 \%$ & $82 \%$ & $1 \%$ & $0 \%$ & $0 \%$ \\
\hline ES & $19 \%$ & $78 \%$ & $3 \%$ & $0 \%$ & $0 \%$ \\
\hline GO & $21 \%$ & $79 \%$ & $0 \%$ & $0 \%$ & $0 \%$ \\
\hline MA & $15 \%$ & $84 \%$ & $1 \%$ & $0 \%$ & $0 \%$ \\
\hline MG & $28 \%$ & $71 \%$ & $2 \%$ & $0 \%$ & $0 \%$ \\
\hline MS & $35 \%$ & $62 \%$ & $0 \%$ & $1 \%$ & $1 \%$ \\
\hline MT & $26 \%$ & $74 \%$ & $0 \%$ & $0 \%$ & $0 \%$ \\
\hline PA & $14 \%$ & $83 \%$ & $2 \%$ & $0 \%$ & $1 \%$ \\
\hline PB & $22 \%$ & $77 \%$ & $0 \%$ & $0 \%$ & $0 \%$ \\
\hline PE & $13 \%$ & $83 \%$ & $1 \%$ & $0 \%$ & $3 \%$ \\
\hline PI & $16 \%$ & $84 \%$ & $0 \%$ & $0 \%$ & $0 \%$ \\
\hline PR & $66 \%$ & $33 \%$ & $0 \%$ & $0 \%$ & $0 \%$ \\
\hline RJ & $26 \%$ & $72 \%$ & $0 \%$ & $0 \%$ & $3 \%$ \\
\hline RN & $27 \%$ & $72 \%$ & $0 \%$ & $0 \%$ & $0 \%$ \\
\hline RO & $21 \%$ & $77 \%$ & $1 \%$ & $0 \%$ & $0 \%$ \\
\hline $\mathbf{R R}$ & $12 \%$ & $81 \%$ & $0 \%$ & $3 \%$ & $4 \%$ \\
\hline RS & $68 \%$ & $30 \%$ & $0 \%$ & $0 \%$ & $2 \%$ \\
\hline SC & $56 \%$ & $42 \%$ & $1 \%$ & $0 \%$ & $0 \%$ \\
\hline SE & $11 \%$ & $86 \%$ & $2 \%$ & $0 \%$ & $1 \%$ \\
\hline SP & $44 \%$ & $56 \%$ & $0 \%$ & $0 \%$ & $0 \%$ \\
\hline To & $19 \%$ & $78 \%$ & $3 \%$ & $0 \%$ & $0 \%$ \\
\hline Brasil & $35 \%$ & $64 \%$ & $1 \%$ & $0 \%$ & $1 \%$ \\
\hline
\end{tabular}

Fonte: INFOPEN (2017).

Para além dos dados apresentados é imprescindível que façamos outros apontamentos sobre as características da trajetória e quanto ao processamento dos fatos sociais qualificados como crimes que envolveram esses indivíduos. Para nós, o furto é um delito que, majoritariamente, exprime a criminalização da miséria, "complemento indispensável da impossibilidade do trabalho assalariado precário e subremunerado como a negação cívica, assim como o desdobramento dos programas sociais num sentido restritivo e punitivo que lhe é concomitante" (WACQUANT, 1999, p. 63). Por essa razão, destrinchar o perfil de parcela dos encarcerados brasileiros, especialmente do Nordeste, impõe uma abordagem conjugada das variáveis raça, classe e educação, trazendo, portanto, não apenas impactos da cor da pele e das condições socioeconômicas, mas também da escolaridade nas trajetórias dos sujeitos. 


\section{A EDUCAÇÃO E O ENCARCERAMENTO EM ARAPIRACA}

Entre aqueles processados por furto nos processos analisados, 2,88\% possuíam o ensino médio, 22, I 1\%, o ensino fundamental, 53,84\%, tinham sido apenas alfabetizados e 21, I5\%, eram analfabetos. Já em relação aos acusados de roubo, 5,31\% possuíam o ensino médio, 32,97\%, o ensino fundamental, 54,25\% tinham sido alfabetizados, enquanto 7,44\%, eram analfabetos. Por último, em relação aos processados por estelionato, 31,03\%, tinham o ensino superior, 55, 17\%, o ensino médio, 10,34\% eram alfabetizados e 3,44\%, ensino fundamental.

\section{Gráfico 7 - Escolaridade dos criminalizados e/ou presos conforme o crime praticado}

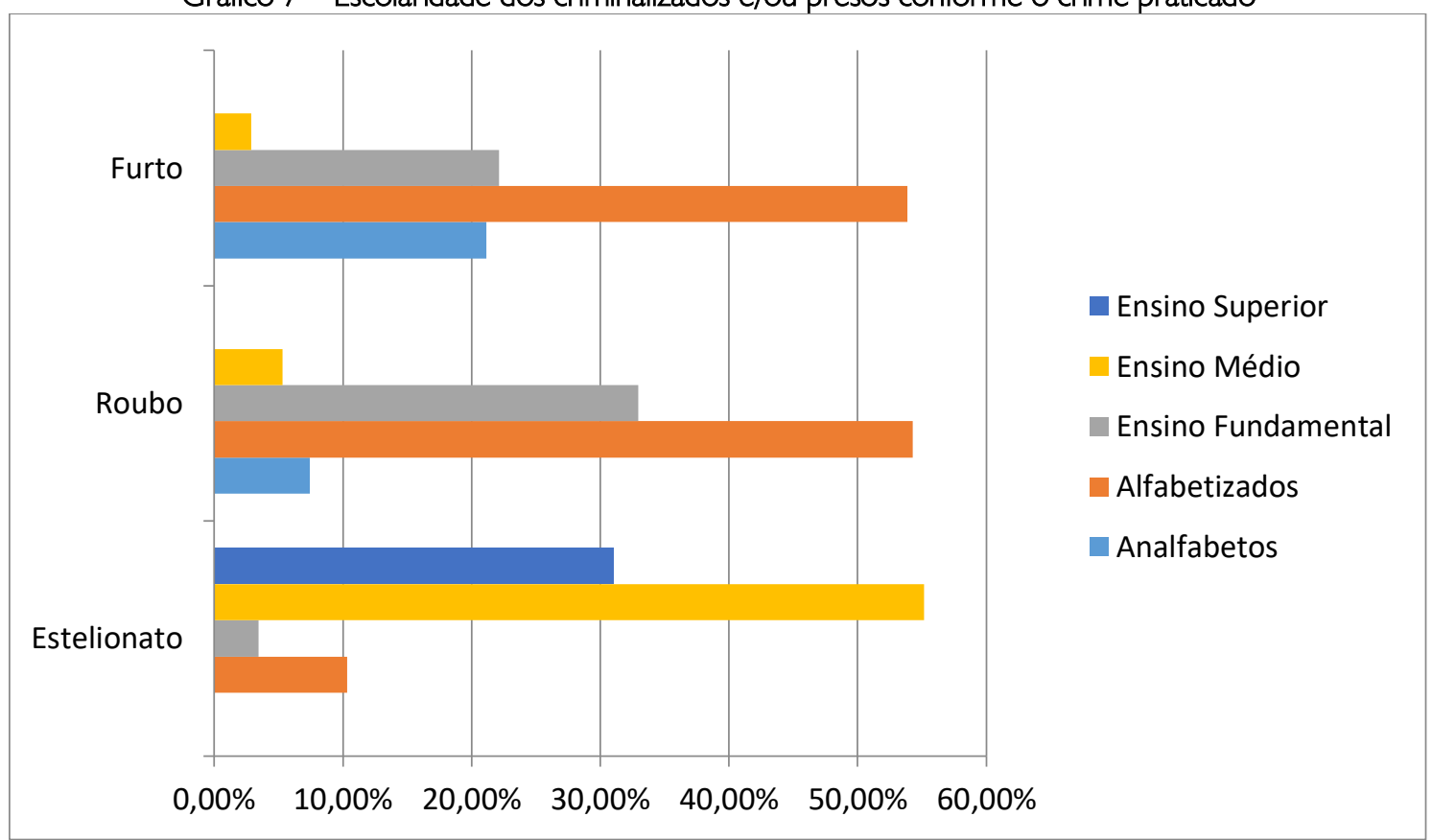

Fonte: elaboração própria (2020).

É necessário dizer que, no tocante à realidade do interior alagoano observada por nós, se fizéssemos uma releitura desse cálculo para o Índice de Exclusão Social, os indicadores de alfabetização e escolaridade teriam de ser considerados com peso igual ou maior do que o da pobreza e emprego. Isso porque, tendo em vista a situação apreciada, a alfabetização ainda não atinge parte considerável da população alagoana, o analfabetismo é uma questão alarmante. A escolaridade é uma exceção à regra, apenas 29 das 321 pessoas processadas terem cursado o ensino médio. Além disso, todas as 09 pessoas com ensino superior estavam sendo processadas por estelionato, sendo que não havia um analfabeto sequer respondendo judicialmente por estelionato nesses processos. Outro ponto a ser lembrado é que $62 \%$ dos acusados por esse crime eram brancos e 100\% deles possuía emprego formal.

A importância em se observar a escolaridade reside no fato de nas sociedades profissionais modernas, em grande medida, a renda ser resultado dos anos de estudo (ELIAS, 200 I; MILLS, 1969). No entanto essa variável não pode ser tomada de maneira ingênua. Em recente pesquisa, Carvalhaes e Ribeiro 
(2019) escreveram sobre a estratificação horizontal da educação no Brasil. A partir de dados coletados e construídos, os autores objetivaram compreender o contexto da expansão educacional brasileira no tocante ao ensino superior e a possível permanência de desigualdades estruturais (de gênero, raça e classe), apesar dos avanços na inclusão de minorias (como as cotas raciais) nas últimas duas décadas. Dos resultados que obtiveram, os pesquisadores chegaram a conclusões que apontaram a persistência de desigualdades estruturais não obstante às ampliações no sistema educacional e às inclusões de grupos sociais antes pouco presentes no ensino superior, tais quais os negros e os filhos das classes populares.

Dentre as razões para tais constatações, a trajetória pregressa das pessoas antes da entrada no ensino superior possui lugar significativo, uma vez que o gênero e a raça interferem nas oportunidades dos indivíduos antes mesmo da possibilidade de ou quando do ingresso no ensino superior. Dito de outro modo, até quando conseguem entrar numa universidade, os negros têm grandes chances de ser alocados em cursos de menor prestígio no mercado de trabalho e, por outro lado, possuem chances reduzidas de acesso aos cursos mais prestigiados. "Isso se explica porque a seletividade do sistema educacional prejudica os negros em pontos anteriores do sistema educacional" (CARVALHAES \& RIBEIRO, 2019).

Por essa razão, a educação formal mínima, alfabetização e escolarização é pressuposto para a qualificação e, consequentemente, possibilidade de adaptação à ordem social competitiva nas sociedades contemporâneas de mercado, como a brasileira (HASENBALG, 1976 e SOUZA, 2009). Em Alagoas, não obstante, a maioria de a população ser composta por jovens, pode-se perceber que grande parte desses jovens não tem conseguido permanecer vinculada à escola, logo, dificilmente terá condições de concorrer por empregos formais e melhoria de vida.

O ensino fundamental brasileiro é uma das etapas da educação básica no Brasil e está regulamentado e assegurado pela lei de Diretrizes e Bases da Educação Brasileira, de 1996, composto pela classe de alfabetização (primeiro ano) até a oitava série (nono ano). $\bigcirc$ estudante que ingressa no ensino fundamental permanece nele, em média, dos seis aos quatorze anos de idade. Para cotejar a posição de Arapiraca com os demais municípios brasileiros com o seu perfil demográfico e populacional, poderíamos, por exemplo, utilizar o Índice de Desenvolvimento Humano Municipal - IHDM. Esse índice incorpora no seu cálculo as variáveis educação (acesso ao conhecimento) e renda (padrão de vida). Compreendemos, todavia, que a plataforma de dados do IBGE é mais completa, por fornecer indicadores mais precisos, pois, no caso de trabalho/rendimento (chamado pelo IDHM de padrão de vida), fornece apenas a renda geral per capta. Além do mais, os dados contidos no IDHM se referem ao ano de 20I0, já a plataforma do IBGE disponibiliza dados de 2015.

Quando comparados com os de outros municípios com perfil populacional semelhante, os indicadores educacionais e de renda de Arapiraca situam-na em posições inferiores à grande maioria dessas cidades. Como se verá na tabela abaixo, o município possui uma das menores notas do IDEB nas séries 
finais do ensino médio. No Brasil, apenas três localidades possuem uma nota inferior a Arapiraca. Dos trinta e três municípios com uma população entre 200 e 250 mil habitantes, a segunda maior cidade de Alagoas, possui a terceira pior nota, empatando com outros dois municípios, Itaboraí (RJ) e Juazeiro (BA). Em âmbito nacional, dos 5.570 munícipios brasileiros, Arapiraca ocupa a posição 3.6990, o que a situa no grupo dos 1.900 municípios com as piores notas do IDEB nas séries finais do ensino fundamental.

Escolhemos o indicador nota do IDEB nas séries finais do ensino fundamental por três razões. Primeiro, o ensino fundamental constitui um momento demasiado relevante para a incorporação de saberes formais e competências intelectuais que serão exigidas, mais à frente, para o ingresso em cursos técnicos profissionalizantes, o próprio ensino médio e o desempenho de funções que exigem, no mínimo, o ensino médio completo. A incorporação desses saberes está diretamente vinculada aos critérios profissionais de empregabilidade, obtenção de renda, ingresso no mercado de trabalho e inserção na ordem social competitiva (FERNANDES, 20/4).

A nota do IDEB nas séries finais do ensino médio pode captar e traduzir melhor o processo de escolarização, letramento e incorporação de saberes formais (como o domínio da fala e certa capacidade de abstração) do que a nota do IDEB nas séries iniciais, uma vez que, na sua grande maioria, as crianças avaliadas nas séries iniciais (entre seis e dez anos de idade) chegam na escola, principalmente na periferia das regiões Norte e Nordeste, marcadas por contextos de privação, violência doméstica, violência urbana e exclusão social.

Tabela 6 - IDEB - anos finais do ensino fundamental - posição dos municípios brasileiros com população entre 200 e 250 mil habitantes

\begin{tabular}{|c|c|c|c|}
\hline \multirow{2}{*}{ Município } & \multirow{2}{*}{ Estado } & Variável - Educação & Posição \\
\cline { 4 - 4 } & & $\begin{array}{c}\text { IDEB - anos finais do ensino } \\
\text { fundamental }\end{array}$ & De 5.570 municípios \\
\hline Arapiraca & AL & 3,7 & $3699^{\circ}$ \\
\hline Araraquara & SP & 4,8 & $1150^{\circ}$ \\
\hline Alvorada & RS & 3,3 & $4460^{\circ}$ \\
\hline Americana & SP & 5,2 & $406^{\circ}$ \\
\hline Cotia & SP & 4,5 & $1890^{\circ}$ \\
\hline Colombo & PR & 3,8 & $3501^{\circ}$ \\
\hline Cabo Frio & RJ & 3,8 & $3501^{\circ}$ \\
\hline Chapecó & SC & 5,1 & $537^{\circ}$ \\
\hline Cabo de Santo Agostinho & PE & 3,5 & $4095^{\circ}$ \\
\hline Criciúma & SC & 4,6 & $1630^{\circ}$ \\
\hline Dourados & MS & 4,2 & $2638^{\circ}$ \\
\hline Divinópolis & MG & 5,1 & $537^{\circ}$ \\
\hline Hortolândia & SP & 4,8 & $1150^{\circ}$ \\
\hline Indaiatuba & SP & 5,2 & $406^{\circ}$ \\
\hline
\end{tabular}




\begin{tabular}{|c|c|c|c|}
\hline Itaboraí & RJ & 3,7 & $3699^{\circ}$ \\
\hline Itapevi & SP & 4,4 & $2134^{\circ}$ \\
\hline Itabuna & $\mathrm{BA}$ & 3,4 & $4237^{\circ}$ \\
\hline Jacareí & SP & 4,8 & $1150^{\circ}$ \\
\hline Juazeiro & BA & 3,7 & $3699^{\circ}$ \\
\hline Maracanaú & CE & 4,7 & $1402^{\circ}$ \\
\hline Marília & SP & 5,0 & $723^{\circ}$ \\
\hline Magé & RJ & 3,9 & $3305^{\circ}$ \\
\hline Parauapebas & PA & 4,6 & $1630^{\circ}$ \\
\hline Presidente Prudente & SP & 4,5 & $1890^{\mathrm{a}}$ \\
\hline Jacareí & SP & 4,8 & $1150^{\circ}$ \\
\hline Rondonópolis & MT & 4,7 & $1402^{\circ}$ \\
\hline Rio Verde & $\mathrm{GO}$ & 5,2 & $406^{\circ}$ \\
\hline Rio Claro & SP & 4,4 & $2134^{\circ}$ \\
\hline Rio Grande & RS & 3,8 & 3501 \\
\hline Santa Luzia & MG & 4,1 & $2875^{\circ}$ \\
\hline Sobral & CE & 6,3 & $6^{\circ}$ \\
\hline São Leopoldo & RS & 3,8 & $3501^{\circ}$ \\
\hline Sete Lagoas & MG & 4,5 & $1890^{\circ}$ \\
\hline
\end{tabular}

Fonte: elaborada a partir do IBGE (2017).

O baixo desempenho do município de Arapiraca junto ao IDEB pode ter sido agravado em razão da redução de matrículas no ensino fundamental entre 2005 e 2015, e a manutenção dos mesmos números de matriculados no ensino médio durante esse mesmo período. Da mesma forma, ocorreu uma redução das matrículas no ensino superior, ocorrendo tão somente uma elevação das matrículas no ensino pré-escolar. 
Gráfico 8 - Matrículas realizadas no ensino pré-escolar, ensino fundamental, ensino médio e ensino fundamental - Arapiraca (2005-2015)

Matrículas (Unidade: matrículas)


Fonte: IBGE (2017)

Tabela 7 - Taxa de Abandono/Evasão no Ensino Fundamental - 2012-20I 5 (em \%)

\begin{tabular}{ccccc} 
BR/NE/AL & 2012 & 2013 & 2014 & 2015 \\
\hline Brasil & 2,7 & 2,2 & 2,2 & 1,9 \\
\hline Nordeste & 4,4 & 3,7 & 3,5 & 3,1 \\
\hline Alagoas & 7,5 & 6,4 & 5,7 & 5,1 \\
\hline
\end{tabular}

Fonte: IBGE/PNAD (20|4).

Se a taxa de abandono/evasão no Ensino Fundamental em Alagoas supera as relativas ao Nordeste e ao Brasil, o que já é uma constatação sensível, sobretudo em um estado cuja maioria de sua população é de jovens e deles depende para a projeção futura dos mecanismos de ascensão socioeconômica; à medida que o índice de escolaridade formal avança, entre ensino básico e ensino superior, o abandono e a evasão dos alunos também aumenta, ou seja, a concentração de estudantes nos ensinos básico e fundamental é proporcionalmente maior à concentração constatada nos ensinos médio e superior. Esse é um fenômeno que temos percebido nos processos pesquisados, nos quais o número de indivíduos que conseguiu concluir o Ensino Médio é irrisório.

Tabela 8 - Taxa de Abandono/Evasão no Ensino Médio - 20I2-20I5 (em \%)

\begin{tabular}{ccccc} 
BR/NE/AL & 2012 & 2013 & 2014 & 2015 \\
\hline Brasil & 9,1 & 8,1 & 7,6 & 6,8 \\
\hline Nordeste & 12,5 & 9,7 & 9,3 & 8,0 \\
\hline Alagoas & 18,2 & 14,9 & 13,9 & 13,8 \\
\hline
\end{tabular}

Fonte: IBGE/PNAD (20|4). 
As informações trazidas pelo INFOPEN (2017) mostram que a escolaridade dos presos brasileiros, em geral, apresenta uma realidade preocupante. Ainda assim, das 27 unidades federativas, a população em situação de prisão em Alagoas é a que possui o menor percentual de ensino fundamental completo, estando empatada com Bahia, Paraíba e Piauí. Inferior ao percentual de Alagoas apenas o estado de Pernambuco. Além disso, Alagoas é o estado com o maior percentual de analfabetos e alfabetizados (sem cursos regulares), três vezes maior que a média nacional. Logo, não se trata de coincidência que o segundo maior município do estado, Arapiraca, possua uma nota tão baixa junto às séries finais do IDEB, pois parte significativa da população não conclui o ensino fundamental, principalmente o contingente populacional submetido ao contexto de extrema pobreza, como ocorre em Arapiraca.

Tabela 9 - Escolaridade das pessoas privadas de liberdade por Unidade da Federação

\begin{tabular}{|c|c|c|c|c|c|c|c|c|c|}
\hline UF & Analfabeto & $\begin{array}{c}\text { Alfabetizado } \\
\text { (sem cursos } \\
\text { regulares) }\end{array}$ & $\begin{array}{c}\text { Ensino } \\
\text { Fundamental } \\
\text { Incompleto }\end{array}$ & $\begin{array}{c}\text { Ensino } \\
\text { Fundamental } \\
\text { Completo }\end{array}$ & $\begin{array}{l}\text { Ensino Mèdio } \\
\text { Incompleto }\end{array}$ & $\begin{array}{l}\text { Ensino Médio } \\
\text { Completo }\end{array}$ & $\begin{array}{l}\text { Ensino Superior } \\
\text { Incompleto }\end{array}$ & $\begin{array}{l}\text { Ensino Superior } \\
\text { Completo }\end{array}$ & $\begin{array}{l}\text { Ensino acima de } \\
\text { Superior Completo }\end{array}$ \\
\hline$A C$ & $6 \%$ & $6 \%$ & $59 \%$ & $11 \%$ & $11 \%$ & $6 \%$ & $0 \%$ & $0 \%$ & $0 \%$ \\
\hline AL & $23 \%$ & $11 \%$ & $48 \%$ & $7 \%$ & $6 \%$ & $4 \%$ & $0 \%$ & $0 \%$ & $0 \%$ \\
\hline AM & $1 \%$ & $1 \%$ & $65 \%$ & $8 \%$ & $12 \%$ & $11 \%$ & $1 \%$ & $0 \%$ & $0 \%$ \\
\hline $\mathrm{AP}$ & $2 \%$ & $3 \%$ & $49 \%$ & $11 \%$ & $20 \%$ & $13 \%$ & $1 \%$ & $1 \%$ & $0 \%$ \\
\hline BA & $10 \%$ & $15 \%$ & $52 \%$ & $7 \%$ & $9 \%$ & $6 \%$ & $0 \%$ & $0 \%$ & $0 \%$ \\
\hline CE & $7 \%$ & $27 \%$ & $45 \%$ & $8 \%$ & $6 \%$ & $5 \%$ & $1 \%$ & $0 \%$ & $0 \%$ \\
\hline DF & $2 \%$ & $1 \%$ & $58 \%$ & $10 \%$ & $16 \%$ & $10 \%$ & $2 \%$ & $1 \%$ & $0 \%$ \\
\hline ES & $3 \%$ & $6 \%$ & $53 \%$ & $9 \%$ & $16 \%$ & $11 \%$ & $1 \%$ & $1 \%$ & $0 \%$ \\
\hline GO & $7 \%$ & $16 \%$ & $35 \%$ & $18 \%$ & $15 \%$ & $8 \%$ & $1 \%$ & $0 \%$ & $0 \%$ \\
\hline MA & $13 \%$ & $16 \%$ & $38 \%$ & $11 \%$ & $13 \%$ & $9 \%$ & $0 \%$ & $0 \%$ & $0 \%$ \\
\hline MG & $3 \%$ & $7 \%$ & $57 \%$ & $13 \%$ & $13 \%$ & $7 \%$ & $1 \%$ & $0 \%$ & $0 \%$ \\
\hline MS & $2 \%$ & $4 \%$ & $59 \%$ & $13 \%$ & $11 \%$ & $9 \%$ & $1 \%$ & $1 \%$ & $0 \%$ \\
\hline MT & $6 \%$ & $9 \%$ & $35 \%$ & $17 \%$ & $18 \%$ & $11 \%$ & $3 \%$ & $1 \%$ & $0 \%$ \\
\hline PA & $5 \%$ & $8 \%$ & $58 \%$ & $10 \%$ & $11 \%$ & $7 \%$ & $0 \%$ & $0 \%$ & $0 \%$ \\
\hline PB & $14 \%$ & $29 \%$ & $42 \%$ & $7 \%$ & $5 \%$ & $4 \%$ & $0 \%$ & $0 \%$ & $0 \%$ \\
\hline $\mathrm{PE}$ & $19 \%$ & $26 \%$ & $34 \%$ & $5 \%$ & $9 \%$ & $5 \%$ & $1 \%$ & $0 \%$ & $0 \%$ \\
\hline PI & $8 \%$ & $18 \%$ & $52 \%$ & $7 \%$ & $9 \%$ & $5 \%$ & $1 \%$ & $1 \%$ & $0 \%$ \\
\hline PR & $0 \%$ & $2 \%$ & $64 \%$ & $9 \%$ & $15 \%$ & $8 \%$ & $1 \%$ & $1 \%$ & $0 \%$ \\
\hline RJ & $2 \%$ & $3 \%$ & $65 \%$ & $15 \%$ & $8 \%$ & $6 \%$ & $1 \%$ & $0 \%$ & $0 \%$ \\
\hline $\mathrm{RN}$ & $13 \%$ & $13 \%$ & $50 \%$ & $10 \%$ & $8 \%$ & $5 \%$ & $1 \%$ & $0 \%$ & $0 \%$ \\
\hline RO & $5 \%$ & $10 \%$ & $52 \%$ & $12 \%$ & $12 \%$ & $8 \%$ & $1 \%$ & $0 \%$ & $0 \%$ \\
\hline RR & $2 \%$ & $12 \%$ & $32 \%$ & $18 \%$ & $17 \%$ & $15 \%$ & $2 \%$ & $1 \%$ & $0 \%$ \\
\hline RS & $3 \%$ & $6 \%$ & $56 \%$ & $17 \%$ & $10 \%$ & $6 \%$ & $1 \%$ & $0 \%$ & $0 \%$ \\
\hline SC & $3 \%$ & $7 \%$ & $48 \%$ & $18 \%$ & $12 \%$ & $10 \%$ & $1 \%$ & $1 \%$ & $0 \%$ \\
\hline SE & $5 \%$ & $6 \%$ & $68 \%$ & $10 \%$ & $6 \%$ & $5 \%$ & $0 \%$ & $0 \%$ & $0 \%$ \\
\hline SP & $2 \%$ & $3 \%$ & $45 \%$ & $17 \%$ & $19 \%$ & $12 \%$ & $1 \%$ & $0 \%$ & $0 \%$ \\
\hline то & $7 \%$ & $9 \%$ & $48 \%$ & $12 \%$ & $14 \%$ & $9 \%$ & $1 \%$ & $1 \%$ & $0 \%$ \\
\hline Brasil & $4 \%$ & $6 \%$ & $51 \%$ & $14 \%$ & $15 \%$ & $9 \%$ & $1 \%$ & $0 \%$ & $0 \%$ \\
\hline
\end{tabular}

Fonte: INFOPEN (2017).

As pesquisas e reflexões teóricas feitas por Hasenbalg e Silva (1988) e por Carvalhaes e Ribeiro (2019) - e tomando por parâmetro comparativo as estatísticas já mencionadas do IDEB, às quais demonstram uma dificuldade acentuada dos estudantes em regiões periféricas como Alagoas e Arapiraca de avanço nos níveis da educação básica, mais ainda, de concluírem o ensino médio - mostram que o ingresso no ensino superior depende intrinsecamente de momentos anteriores na trajetória desses indivíduos. No caso dos negros, maioria expressiva dos criminalizados por furto, trata-se de um "ciclo 
cumulativo de desvantagens", evidente tanto na escolarização que, inclusive, é decorrente da escolarização herdada de seus pais, quanto na dificuldade de inserção no mercado de trabalho formal e informal como vimos anteriormente (HASENBALG E SILVA, 1988).

\section{CONCLUSÃO}

A pesquisa constatou formas de punição não formal por parte do sistema de justiça criminal, relativas à trajetória dos presos sem condenação e não ao ato criminoso em si, tais quais os marcadores sociais da diferença e do estigma, como a cor da pele, a pouca desenvoltura diante das autoridades do sistema de justiça criminal, resultante da baixa escolaridade, e a ausência de ocupação. Concluiu-se, tomando como comparativo os perfis dos acusados por furto e por estelionato, que o aprisionamento provisório é muito mais resultado das avaliações e julgamentos subjetivos e intersubjetivos dos agentes do sistema de justiça criminal sobre a trajetória dos acusados do que uma aplicação estrita da legislação.

Os dados coletados a partir dos processos levantados junto à $5^{\mathrm{a}}$ vara criminal de Arapiraca, especialmente as variáveis relativas ao perfil dos presos, coadunam-se com os dados nacionais e estaduais acerca do encarceramento em massa. Já os dados específicos acerca das variáveis emprego/rendimento e educação no município de Arapiraca alargam a compreensão para explicar as determinações que atravessam e constituem as trajetórias dos indivíduos que residem nesse município.

Nesse sentido, as principais constatações feitas foram quanto ao comparativo dos distintos perfis de acusados por furto e de acusados por estelionato e como o sistema de justiça criminal apreendia o fato criminoso e julgava essas pessoas, mesmo considerando que formalmente o crime de furto e o de estelionato são semelhantes em termos de penas estabelecidas no Código Penal Brasileiro. Não obstante, percebemos que por estarem mais aptos à ordem social competitiva e não possuírem marcadores de estigma - todos estavam empregados formalmente, todos foram atendidos por advogado particular, a maioria era branca, todos eram escolarizados - os indivíduos investigados por estelionato foram favorecidos durante o processo, de forma que apenas uma pessoa foi presa provisoriamente, embora tenha sido liberada no dia seguinte.

A investigação feita a partir dos dados primários e conjugada aos dados secundários apresentados no texto levou-nos a concordar com Hasenbalg (1999), quando afirma que a falta de mobilidade dos negros para as posições mais altas na estrutura ocupacional/profissional vincula-se ao que denominou de "ciclo cumulativo de desvantagens". Significa dizer que não apenas a herança escravista tem peso na desigualdade suportada pelos negros brasileiros, mas que, dentro da competição social, em cada fase de suas vidas e das suas trajetórias, operam processos discriminatórios. Tais processos vão desde a aquisição de educação formal ao ingresso no mercado de trabalho. 
Se o Brasil é considerado uma sociedade moderna de tipo periférica, Alagoas, tendo por parâmetro esses dados apresentados, seria a periferia da periferia brasileira. Em todos os quesitos, desde o índice de desenvolvimento humano à educação, longevidade e renda, a desigualdade e o quadro de exclusão no estado estão acima do padrão brasileiro. Para um estado tão pequeno, Alagoas é um território que, arriscamos dizer, mais do que a maioria dos estados brasileiros, concentra uma "ralé estrutural" significativa.

\section{REFERÊNCIAS}

AMANCIO, T. e BASTOS, P. Arapiraca, em Alagoas, lidera ranking de saldo positivo de vagas de emprego. Folha de São Paulo, São Paulo, 21 de fevereiro de 2016. Disponível em: https://wwwl .folha.uol.com.br/mercado/2016/02/I741 524-arapiraca-em-alagoas-lidera-ranking-desaldo-positivo-de-vagas-de-emprego.shtml. Acesso em: 15 maio 2019.

CARVALHAES, F. e RIBEIRO, C. Estratificação horizontal da educação superior no Brasil: Desigualdades de classe, gênero e raça em um contexto de expansão educacional. Tempo social. Vol.3I n. I São Paulo: janeiro/abril, 2019. Disponível: http://www.scielo.br/scielo.php?script=sci arttext\&pid=SOI0320702019000100195. Acesso em: 21 maio 2019.

Departamento Penitenciário Nacional - Ministério da Justiça. Levantamento Nacional de informações penitenciárias. Brasília: INFOPEN, 2014. Disponível em: http://www.justica.gov.br/noticias/mj-divulgaranovo-relatorio-do-infopen-nesta-terca-feira/relatorio-depen-versao-web.pdf. Acesso em: 03 abril 2019.

Departamento Penitenciário Nacional - Ministério da Justiça. Levantamento Nacional de informações penitenciárias. Brasília: INFOPEN, 2017. Disponível em: http://www.justica.gov.br/news/ha-726-7I2pessoas-presas-no-brasil/relatorio_2016 junho.pdf. Acesso em: 03 abril 2019.

NORBERT, Elias. A sociedade de corte: investigação sobre a sociologia da realeza e da aristocracia de corte. Tradução de Pedro Süssekind. Rio de Janeiro: Jorge Zahar Ed., 200 I .

FERNANDES, Florestan. A integração do negro na sociedade de classes (Vol. I). São Paulo: Globo Livros, 2014.

GAZETAWEB e Agência Alagoas. Call center vai gerar cerca de 1600 empregos em Arapiraca. GAZETAWEB, Maceió, 12 de outubro de 2014. Disponível em: http://gazetaweb.globo.com/portal/noticia-old.php?c=379937\&e=6. Acesso em: 05 abril 2019.

Governo de Alagoas. Alagoas em Dados e Informações. Maceió: 20 17. Disponível em: http://dados.al.gov.br/. Acesso em: 28 março 2019.

HASENBALG, C. Discriminação e desigualdades raciais no Brasil. Rio de Janeiro: Graal, 1979.

HASENBALG, C.; SILVA, Nelson. Estrutura social, mobilidade e raça. Rio de Janeiro: Vértice, 1988.

Instituto Brasileiro de Geografia e Estatística (IBGE). Censo Demográfico. Rio de Janeiro: IBGE, 2010. Disponível em: https://censo20 l O.ibge.gov.br/. Acesso em: 23 abril 2019.

Instituto Brasileiro de Geografia e Estatística (IBGE). Pesquisa Nacional por Amostra de Domicílios (PNAD): síntese de indicadores. Rio de Janeiro: IBGE, 20।4. Disponível em:

https://biblioteca.ibge.gov.br/visualizacao/ivros/liv94935.pdf. Acesso em: 23 abril 2019. 
Instituto Brasileiro de Geografia e Estatística (IBGE). IBGE Cidades. Rio de Janeiro: IBGE, 2017. Disponível em: https://cidades.ibge.gov.br. Acesso em: 23 abril 2019.

Instituto Brasileiro de Geografia e Estatística (IBGE). Síntese de indicadores sociais: uma análise das condições de vida da população brasileira: 20 I8. Rio de Janeiro: IBGE, Coordenação de População e Indicadores Sociais, 20 I8. Disponível em: https://biblioteca.ibge.gov.br/visualizacao/ivros/liv I01629.pdf. Acesso em: 23 abril 2019.

CERQUEIRA, Daniel et all (Org.). Atlas da violência no Brasil. Brasília: IPEA e FBSP, 20 I 6. Disponível em: http://www.ipea.gov.br/atlasviolencia/arquivos/downloads/553 I-8031 160322nt I 7atlasdaviolencia20 I 6finalizado.pdf. Acesso em: 05 abril 2019.

MILLS, C. W. A nova classe média (White colar). Tradução de Vera Borda. Rio de Janeiro, 1969, do original norteamericano White Collar, The American Middle Classes, Oxford University Press, I95I.

Programa das Nações Unidas para o Desenvolvimento (PNUD). Relatório do Desenvolvimento Humano de 2014. Disponível em: http://hdr.undp.org/sites/default/files/hdr20l4 pt web.pdf. Acesso em: 03 abril 2019.

Programa das Nações Unidas para o Desenvolvimento (PNUD). Secretaria-Geral da Presidência da República e Secretaria Nacional de Juventude. Mapa do encarceramento: os jovens do Brasil. Brasília: Presidência da República, 20 I5. Disponível em:

http://www.pnud.org.br/arquivos/encarceramento WEB.pdf. Acesso em: 03 abril 2019.

POCHMANN, Márcio (Org.). Atlas da exclusão social no Brasil, Vol 2. A dimensão da exclusão social na primeira década do século XXI. São Paulo: Cortez, 2015.

POCHMANN, Márcio (Org.). Atlas da exclusão social no Brasil: 10 anos depois. São Paulo: Editora Cortez, 2010.

Secretaria de Estado de Ressocialização e Inclusão Social (SERIS). Mapa de Informações Penitenciárias. Maceió: SERIS, 20 17. Disponível em: http://www.seris.al.gov.br/. Acesso em: 03 abril 2019.

Ministério da Saúde. Sistema de Informação sobre Mortalidade (SIM)/Datasus. Brasília: 2013.

SOUZA, Jessé. A ralé brasileira. Quem é e como vive. Belo Horizonte: Editora UFMG, 2009.

TENÓRIO, Douglas Apratto. O mundo do açúcar em Alagoas. In: Caminhos do açúcar: engenhos e casas-grandes das Alagoas. DANTAS, Cármen Lúcia; TENÓRIO, Douglas Apratto. 2 ed. Maceió: Sebrae, 2010.

WACQUANT, Loic. As Prisões da Miséria. Tradução de André Telles. Rio de Janeiro: Zahar, 1999. 